FACTA UNIVERSITATIS

Series: Architecture and Civil Engineering Vol. 10, Nº 2, 2012, pp. 223 - 234

DOI: 10.2298/FUACE1202223D

\title{
THE APPLICATION OF INTERVAL CALCULUS IN ESTIMATION OF DYNAMIC CHARACTERISTICS OF STRUCTURES *
}

\author{
$U D C 624.042 .8: 519.6=111$
}

\section{Đorđe Đorđević, Predrag Petronijević}

University of Niš, Faculty of Civil Engineering and Architecture, Serbia djordje.djordjevic@gaf.ni.ac.rs

\begin{abstract}
The paper analyzed application of interval calculus in estimation of dynamic characteristics of linear systems. The eigen periods of oscillation of structures are affected by several parameters: geometrical characteristics of cross sections of members, magnitude of the mass concentrated in the floors and modulus of elasticity of materials. As a numerical example, the frame reinforced concrete structure was taken, for which the mentioned parameters are given in the form interval. The result is also obtained in the form of interval so it is possible to observe the direct effects on the value of the structural oscillation periods by changing one or several parameters.
\end{abstract}

Key words: interval calculus, eigenfrequency analysis, matrix formulation.

\section{INTRODUCTION}

When designing structures, and especially in the case of calculation of effects of loads variable in time such as the wind, seismic action, influence of machinery and others, it is necessary to determine basic dynamic characteristics of the system. Natural forms and periods of oscillation of frame structures can be determined by the methods worked out in the structural dynamics [1-3]. There is a number of approximate methods for determining forms and periods of oscillation, as for instance the Holzer procedure or iterative method of gradual approximation [4,5]. In the analysis phase of the potential structural system, the estimation of period an form of oscillation is particularly important this paper presents

Received November 12, 2012

* Acknowledgement. This research is supported by the Ministry of Science and Technological Development of the Republic of Serbia, within the framework of the Technological Development project TR36016 for project cycle 2011-2014, "Experimental and theoretical investigation of frames and plates with semi-rigid connections from the view of the second order theory and stability analysis" and TR36028 for project cycle 2011-2014, "Development and improvement of methods for analyses of soil-structure interaction based on theoretical and experimental research" of the research organization The faculty of civil engineering and architecture of University of Nis. 
the procedure of calculus of periods of oscillation applying interval calculus as a good indicator of dependence of function and dominance of individual variables on the value of the function.

Optimum design of structures requires varying of a large number of parameters. The final choice of the structural system, applied materials, methods of construction and others are the elements which are adopted relatively easily, at the start of designing. Calculus of influence and design of structural elements depends on the large number of factors and an optimal and rational solution is often a result of numerous iterations. When solving such complex problems, it is recommended to have a review of impacts of input parameters on the final result. The paper presents the problem of determination of eigenfrequencies of the frame in plane loaded by the gravitation. The parameters directly affecting the final value of the oscillation periods also affect the relationship between the maximal and minimal value of the function. Setting some input data in the form of a closed interval $\left[x_{\min }, x_{\max }\right]$ we obtain the results in the same form, so it is possible to draw certain conclusions towards final adoption of a structural element. Or, more important, it becomes possible to see whether the parameter is dominant or peripheral, i.e. which parameters would produce the desired results in the easiest way. Estimation of magnitude of oscillation period was performed by solving the homogeneous differential equation of free oscillations. The interval calculus will be shown through certain numerical examples.

\section{NON-DAMPENED OSCILLATIONS OF LINEAR BEAMS}

We are observing a linear system composed of straight members whose masses are distributed along their axes. Let there be in every node of the system a concentrated mass $\mathbf{m}_{\mathbf{i}}$ which is connected eccentrically in the node $\mathbf{j}$ with the inertia radius $\mathbf{r}_{\mathbf{j}}$. In Fig. 1 is presented the member having length 1 , of a constant cross section which is exposed to bending in the plane xoy of the local coordinate system. If the impacts of normal forces on deformation of the member are neglected, the generalized displacements are transversal displacements $\left(\vartheta_{i}, \vartheta_{\mathrm{k}}\right)$ and rotations $\left(\varphi_{i}, \varphi_{\mathrm{k}}\right)$ of the ends of the member, so the element has four degrees of freedom - two in each node. The generalized forces are transversal forces $\left(\mathbf{T}_{\mathbf{i}}, \mathbf{T}_{\mathbf{k}}\right)$ and moments $\left(\mathbf{M}_{\mathrm{i}}, \mathbf{M}_{\mathbf{k}}\right)$ in nodes i,k.

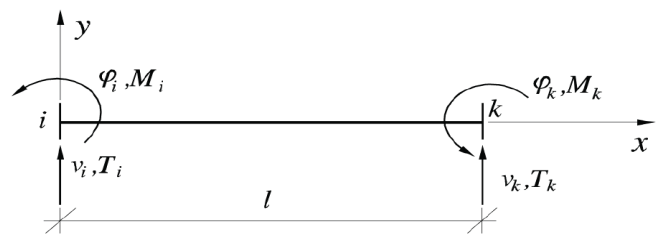

Fig. 1. Generalized displacements and generalized forces at the ends of a beam

Equations derived so far refer to the local coordinate system of the beam. For the analysis of systems of connected members, as a whole, it is necessary to define the position of each member relative to the global coordinate system, so that all values must be transformed in relation to the global system. If the equation (9), valid for any member of the system, 


$$
\mathbf{R}=\mathrm{ku}-\mathrm{q}
$$

where it is:

$\mathbf{R}$ - Vector of generalized forces,

$\mathrm{k}$ - Stiffness matrix of the member,

$\mathrm{u}$ - Vector of generalized displacements,

$q$ - Vector of equivalent load of the member.

Coefficients of member stiffness matrix can be determined as reactions of a member fixed on both ends due to generalized displacement (unit displacement and rotation of the ends of the member), whereby all the other generalized displacement are equal to zero.

The stiffness matrix of a member rigidly fixed at the ends exposed to bending has familiar form, whose members are simply determined by the widely known procedure from the matrix formulation of linear systems [1].

The elements of load vector for different external loads are given in the form of the tables. It can be said that for each member $\mathbf{i}$ the following relation holds:

$$
\begin{gathered}
R_{i}=k_{i} u_{i}-q_{i} \\
q=-m \ddot{u} \\
R_{i}=k_{i} u_{i}-m \ddot{u}_{i}
\end{gathered}
$$

Where $R j$ is a vector of forces on the ends of the member in local coordinated system. Using the member transformation matrix, the expressions for displacement $U$ and acceleration $\ddot{U}$, which represent the components of displacement, that is acceleration of the ends of members in a global coordinate system are:

$$
\begin{gathered}
U_{i}=T_{i} u_{i} \\
\ddot{U}_{i}=-T_{i} \ddot{u}_{i} \\
R_{i}=k_{i} T_{i} U_{i}-M_{i} T_{i} \ddot{U}_{i}
\end{gathered}
$$

When the member is observed as an independent element which is separated from the system, it is observed in a local coordinate system. Its beginning is in the node and on the left end of the member, the $\mathrm{x}$ axis coincides with the axis of the member, and the axes $\mathrm{y}$ and $\mathrm{z}$ coincide with the main axes of inertia of the cross section of the member. In this way, each member has its local coordinate system.

When we observe a system of members, as a whole, it is necessary to determine the position of each member in respect to a common system, which is called the reference, general or global coordinate system. That is why it is necessary to perform transformation of the vector of generalized forces (displacements) and the stiffness matrix from the local into global coordinate system.

$$
\begin{gathered}
R_{i}^{*}=T_{i}^{T} R_{i} \\
R_{i}^{*}=T_{i}^{T} k_{i} T_{i} U_{i}+T_{i}^{T} M_{i} T \ddot{U_{i}} \\
k_{i}^{*}=T_{i}^{T} k_{i} T_{i} \\
m_{i}^{*}=T_{i}^{T} m_{i} T_{i}
\end{gathered}
$$


$R_{i}^{*}$ - vector of forces on the ends of the member in global coordinate system

$k_{i}^{*}-$ member stiffness matrix in global coordinate system

$m_{i}^{*}$ - member mass matrix in global coordinate system

$$
R_{i}^{*}=k_{i}^{*} U_{i}-M_{i}^{*} \ddot{U}_{i}
$$

If D'Alambert principle is applied, and by marking the vector of force on the ends of all members in the global coordinate system with $\mathrm{k}$, the equilibrium equation of nodes for the system of members is:

$$
P+J=R
$$

$P-$ vector of dynamic forces in nodes

$J$ - vector of inertial forces due to movement of masses concentrated in the nodes

$$
J=-M_{c}^{*} \ddot{U}_{i}
$$

Matrix $\mathrm{M}_{\mathrm{c}}$ is given by submatrices $\mathrm{M}_{\mathrm{cj}}$ along the main diagonal of the form:

$$
M_{c j}=m_{j}\left[\begin{array}{ccc}
1 & 0 & 0 \\
0 & 1 & 0 \\
0 & 0 & r_{j}
\end{array}\right]
$$

$r_{j}-$ radius of inertia of eccentrically appended mass $m_{j}$ in node $j$.

Matrix equation of dynamic equilibrium for the discrete system with n-degrees of freedom:

$$
(M+M c) \ddot{U}+K U=P
$$

Where:

$$
\begin{aligned}
& K=\sum_{i=1} k_{i}^{*}-\text { is the stiffness matrix of the entire system, } \\
& M=\sum_{i=1} M_{i}^{*}-\text { mass matrix of the entire system }
\end{aligned}
$$

If the last matrix equation is reworked so that firstly the equilibrium conditions of active and inertial forces in the direction of unknown and then known displacements, the following equation is obtained:

$$
\left[\begin{array}{l}
P_{n} \\
P_{p}
\end{array}\right]=\left[\begin{array}{ll}
M_{n n} & M_{n p} \\
M_{p n} & M_{p p}
\end{array}\right]\left[\begin{array}{l}
\ddot{U}_{n} \\
\ddot{U}_{p}
\end{array}\right]+\left[\begin{array}{ll}
K_{n n} & K_{n p} \\
K_{p n} & K_{p p}
\end{array}\right]\left[\begin{array}{l}
U_{n} \\
U_{p}
\end{array}\right]
$$

\subsection{Free oscillations equation}

In case when there is no external load, and when the supports are not displaced and fixations do not rotate, then:

$$
P_{n}=U_{p}=\ddot{U}_{p}=0
$$

The equation becomes the equation of free oscillations of the beam: 


$$
M_{n n} \ddot{U}+K_{n n} U=0
$$

This homogeneous differential equation has the following solution:

$$
U_{n}=U_{n o} \sin (\omega t+\alpha)
$$

Where $\omega$ is the circular frequency of free non-dampened oscillations, $\alpha$ is the phase, and $\mathrm{U}_{\mathrm{no}}$ is the vector of amplitudes of unknown displacements. By substitution of the solution in the differential equation (20) the following is obtained:

$$
U_{n o}\left(K_{n n}-\omega^{2} M_{n n}\right)=0
$$

Equation 23 has a non-trivial solution only if the system determinant is equal to zero:

$$
\operatorname{det}\left(K_{n n}-\omega^{2} M_{n n}\right)=0
$$

This is an algebraic equation of the n-th order and it is called the frequency equation. By solving this equation the eigenfrequencies $\omega_{1}, \omega_{2}, \omega_{3}, \ldots, \omega_{n}$ of the beam are obtained.

Since $\mathbf{K}_{\mathrm{nn}}$ and $\mathbf{M}_{\mathrm{nn}}$ are positively definite matrices, all the roots of the characteristic polynomial are real positive numbers and represent the eigen values or frequencies of the system. To each eigen value $\omega_{i}$ corresponds one eigenvector $U_{n o i}$ that eigen form, tone or vibration mode. Vectors of eigenforms have property of modal orthogonality that is presented by the following formula:

$$
\left(K_{n n}-\omega^{2} M_{n n}\right) U_{n o i}=0
$$

They possess the characteristic of orthogonality:

$$
\begin{array}{lll}
U_{n i}^{T} M_{n n} U_{n o j}=0 & \text { za } & i \neq j \\
U_{n o i}^{T} K_{n n} U_{n o j}=0 & \text { za } & i \neq j
\end{array}
$$

Solving the problem of eigen values is the most important mathematical problem in dynamics of structures. There is a series of methods facilitating solving of various variants, but there is no optimal method which could be used for all possible cases. To determine the eigen value and eigenvectors of the discrete structure a series of procedures are developed.

\subsection{Equation of beam oscillation with directly concentrated masses}

In case of directly concentrated masses, there is no vector of equivalent inertial nodal load, so the relation between the forces on the ends of the member and movement of the ends of the member is:

$$
R_{i}=k_{i} u_{i}
$$

Further derivation of equations of free oscillations of beams is identical to derivation of equations of free oscillations of beams with equivalent masse, except that in the dynamic equilibrium equation (16) the mass matrix $M$ equals zero, so there is only diagonal mass matrix $M_{c}[1]$. 


\section{AN EXAMPLE OF DETERMINATION OF DYNAMIC CHARACTERISTICS APPLYING INTERVAL CALCULUS}

The matrix form as a method of structural analysis and particularly the method of finite elements is widely used in dynamic analysis of structures in various field of structural engineering. For the frame presented in Fig. 2 for the given intervals of values of dimensions of the member cross section, modulus of elasticity and magnitude of distributed mass, the circular frequencies and periods of oscillation of free horizontal oscillations of the frame were calculated. The following dimensions of cross sections were obtained: all members are in interval from $\mathrm{b} / \mathrm{h}=30 / 30$ to $30 / 60 \mathrm{~cm}$. Modulus of elasticity of concrete was determined according to Regulation $\mathrm{BAB} 87$ from adopted concrete MB 30 it is $\mathrm{E}=$ $31.5 \times 10^{6} \mathrm{kN} / \mathrm{m}^{2}$ to $\mathrm{MB} 40$ it is $\mathrm{E}=34 \times 10^{6} \mathrm{kN} / \mathrm{m}^{2}$, and the evenly distributed mass is adopted according to the width of the perpendicular frame for the mass value of $1 \mathrm{t} / \mathrm{m}^{2}$.
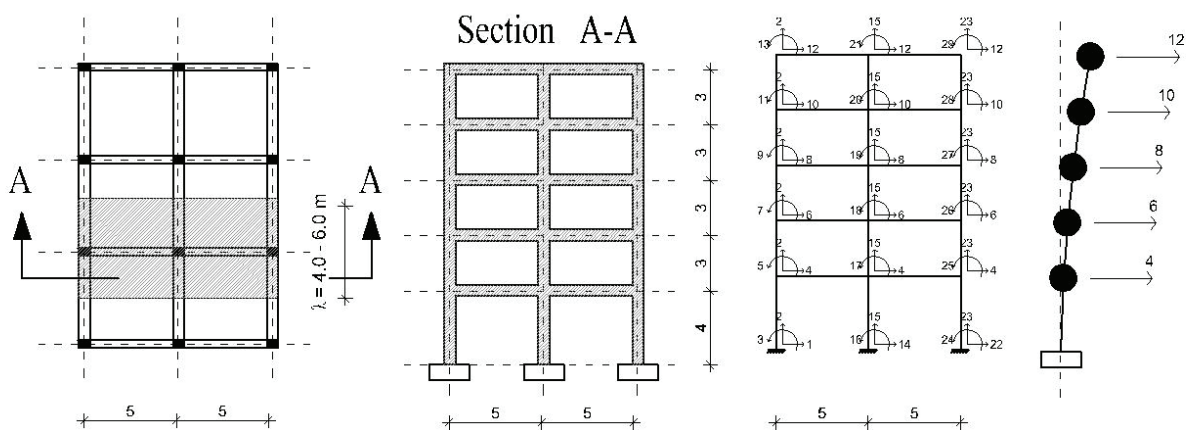

Fig. 2. Floor plan and frame section (left), Generalized displacements (right)

A simpler model was used for the dynamic analysis. Usage of a simpler model is justified by te fact that the behavior of the structure is practically affected only several lowest vibration tones, and usually these tones can be measurably affected only by a small number of degrees of freedom. The transition from the complicated to the simpler dynamical model is performed through the condensation procedure which eliminates only the irrelevant degrees of freedom, and those are, as a rule, those related to small inertial forces with no external load. Inertial force is small if the mass or acceleration is small.

For the frame in Fig. 2 we will not make a big mistake if we neglect the axial forces. By this all the vertical displacements are neglected and all horizontal displacements of all nodes on the same floor are equalized. The eigen forms are most importantly affected by the inertial forces in the horizontal direction so that the nodal rotations are ignored, too. By this the number of degrees of freedom is reduced to five horizontal displacements. The example is illustrated for the case of directly concentrated mass. The matrix of rigidity and mass matrix of the system are taken as finial and calculated to eigen values and eigen vectors in the interval calculus. The graphs illustrated dependencies of the function and the limits of range where it is possible to expect the oscillation periods and system frequencies. The program is written for applications of (24) through all interior grid points. Marks, used to assigned program writing, are shown at Table 1. 
The values of eigen periods are affected by the rigidity of the structure, modulus of elasticity and magnitude of masses concentrated in the nodes of the system. Relation of eigen periods and eigen frequencies is inversely proportionate, i.e the eigen frequencies of higher tones are increasing and eigen periods are decreasing. In the given graphs are presented the interdependencies of dynamic characteristics (periods- $T$ and eigen frequencies - $\mathrm{f}$ ) in the function of every of the parameters (moments of inertia -J, modulus of elasticity - E and distributed mass $-\mu$ ) and with variation in interval calculus of the remaining two variables. All three variables of magnitude are taken to be in real limits. Five tones were presented. The results which are obtained in this example are in character identical with the various cases of frame structure as the form of equations is identical. The resulting conclusions are universal and can be generalized for all the problems of determination of eigen frequencies of classic engineering structures.

Table 1.

\begin{tabular}{clc}
\hline $\begin{array}{c}\text { Program } \\
\text { symbol }\end{array}$ & \multicolumn{1}{c}{ Definition } & $\begin{array}{c}\text { Unit of } \\
\text { measurement }\end{array}$ \\
\hline $\mathrm{J}$ & Moment of inertia & $\mathrm{m}^{4}$ \\
$\mathrm{Em}$ & Young's modulus, $\mathrm{E}$ & $\mathrm{kN} / \mathrm{m}^{2}$ \\
$\mu$ & Distributed mass & $\mathrm{t} / \mathrm{m}$ \\
$\omega$ & Eigen frequency & $\mathrm{rad} / \mathrm{s}$ \\
$\mathrm{Knn}$ & Stiffness matrix of the system & \\
$\mathrm{Mnn}$ & Mass matrix of the system & \\
$\mathrm{Es}$ & Eigensystem & $\mathrm{s}$ \\
$\mathrm{T}$ & Period & $\mathrm{s}$ \\
$\mathrm{f}$ & Characteristic frequency & \\
\hline
\end{tabular}

\section{Main program:}

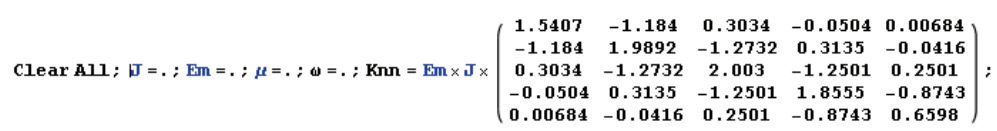

Mnn $=\mu\left(\begin{array}{ccccc}20.5 & 0 & 0 & 0 & 0 \\ 0 & 19 & 0 & 0 & 0 \\ 0 & 0 & 19 & 0 & 0 \\ 0 & 0 & 0 & 19 & 0 \\ 0 & 0 & 0 & 0 & 14.5\end{array}\right) ;$ Es = Ei Eensystem [ Inverse [Mnn] .Knn $\times \mu /($ En $\times$ J $\left.)\right]$; Print [Es ] ;

$\operatorname{Do}\left[\left\{\omega[i]=\sqrt{\operatorname{Es}[[1, i]] \times \frac{\operatorname{Em} \times J}{\mu}}\right\},\{i, 1,5\}\right] ; \mu=\operatorname{Interval}[\{2.300,3.450\}] ; \operatorname{Em}=\operatorname{Interval}\left[\left\{3.15 * 10^{\wedge} 7,3.4 \star 10^{\wedge} 7\right\}\right]$;

$J=$ Interval $\left[\left\{0.25 * 0.4^{\wedge} 3 / 12,0.3 * 0.5 \wedge 3 / 12\right\}\right]$; Print [ DIMAMIČKE KARAKTERISTIKE SISTEMA" $]$;

Do[Print ["Frekfenca $f ", i, "=", 0[6-i] /(2 \mathrm{Pi}), " \mathrm{~Hz}$

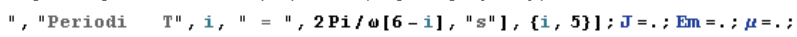

$\operatorname{Do}\left[\left\{\omega[i]=\sqrt{\operatorname{Es}[[1, i]] \times \frac{\operatorname{Em} \times J}{u}}\right\},\{i, 1,5\}\right]$; 


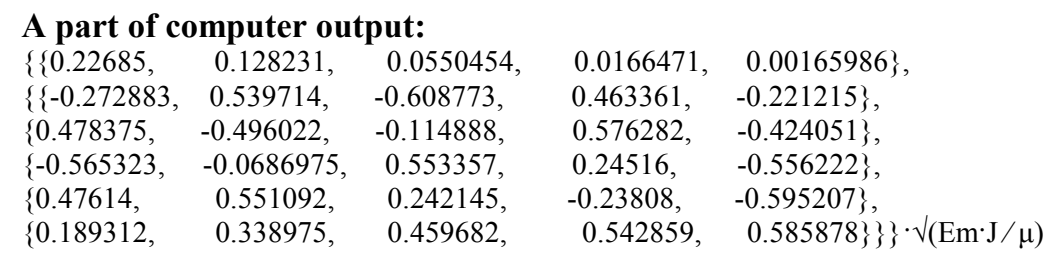

DYNAMIC CHARACTERISTICS OF THE SYSTEM

Frequency f $1=$ Interval $[\{1.09528,2.03557\}] \mathrm{Hz}$

Periods T $1=$ Interval $[\{0.491263,0.913005\}] \mathrm{s}$

Frequency f $2=$ Interval[ $\{3.46864,6.44642\}] \mathrm{Hz}$

Periods T $2=$ Interval $[\{0.155125,0.288297\}] \mathrm{s}$

Frequency f $3=$ Interval $[\{6.30741,11.7222\}] \quad \mathrm{Hz}$

Periods T $3=$ Interval $[\{0.085308,0.158544\}] \mathrm{s}$

Frequency f $4=$ Interval[ $\{9.62692,17.8915\}] \mathrm{Hz}$

Periods T $4=$ Interval $[\{0.0558925,0.103875\}] \mathrm{s}$

Frequency f $5=$ Interval[ $\{12.8044,23.7968\}] \mathrm{Hz}$

Periods T $5=$ Interval $[\{0.0420224,0.078098\}] \mathrm{s}$

I-case: Variation of dynamic characteristics of the structure depending on $\boldsymbol{\mu}$ $\mu=\operatorname{Interval}[\{2.300,3.450\}] ; \operatorname{Plot} 3 \mathrm{D}[\{\operatorname{Max}[(2 \mathrm{Pi}) / \omega[1]], \operatorname{Min}[(2 \mathrm{Pi}) / \omega[1]], \operatorname{Max}[(2 \mathrm{Pi}) / \omega[2]], \operatorname{Min}[(2 \mathrm{Pi}) / \omega[2]]$ $\operatorname{Max}[(2 \mathrm{Pi}) / \omega[3]], \operatorname{Min}[(2 \mathrm{Pi}) / \omega[3]], \operatorname{Max}[(2 \mathrm{Pi}) / \omega[4]], \operatorname{Min}[(2 \mathrm{Pi}) / \omega[4]], \operatorname{Max}[(2 \mathrm{Pi}) / \omega[5]]$, $\operatorname{lin}[(2 \mathrm{Pi}) / 0[5]]\},\left\{\mathrm{J}, .25 * 0.4^{\wedge} 3 / 12, .3 * 0.5^{\wedge} 3 / 12\right\},\left\{\mathrm{Em}, 3.15 * 10^{\wedge} 7,3.40 * 10^{\wedge} 7\right\}$ ，

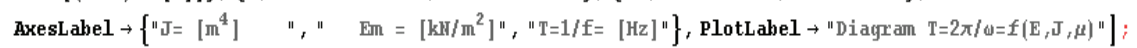
Plot3D $[\{\operatorname{Max}[\omega[1] /(2 \mathrm{Pi})], \operatorname{Min}[\omega[1] /(2 \mathrm{Pi})], \operatorname{Max}[\omega[2] /(2 \mathrm{Pi})], \operatorname{Min}[\omega[2] /(2 \mathrm{Pi})], \operatorname{Max}[\omega[3] /(2 \mathrm{Pi})]$, $\operatorname{Min}[\omega[3] /(2 \mathrm{Pi})], \operatorname{Max}[\omega[4] /(2 \mathrm{Pi})], \operatorname{Min}[\omega[4] /(2 \mathrm{Pi})], \operatorname{Max}[\omega[5] /(2 \mathrm{Pi})], \operatorname{Min}[\omega[5] /(2 \mathrm{Pi})]\}$, $\left\{\mathrm{J}, .25 * 0.4^{\wedge} 3 / 12, .3 * 0.5^{\wedge} 3 / 12\right\},\left\{\mathrm{Em}, 3.15 * 10^{\wedge} 7,3.40 * 10^{\wedge} 7\right\}$,

AxesLabel $\rightarrow\left\{" \mathrm{~J}=\left[\mathrm{m}^{4}\right] \quad\right.$ ", " $\left.\quad \mathrm{Em}=\left[\mathrm{kH} / \mathrm{m}^{2}\right] ", " \mathrm{f}=1 / \mathrm{T}=[\mathrm{Hz}] "\right\}$, PlotLabel $\rightarrow$ "Diagram $\left.\mathrm{f}=\mathrm{\omega} / 2 \pi=f(\mathrm{E}, \mathrm{J}, \mu) "\right]$
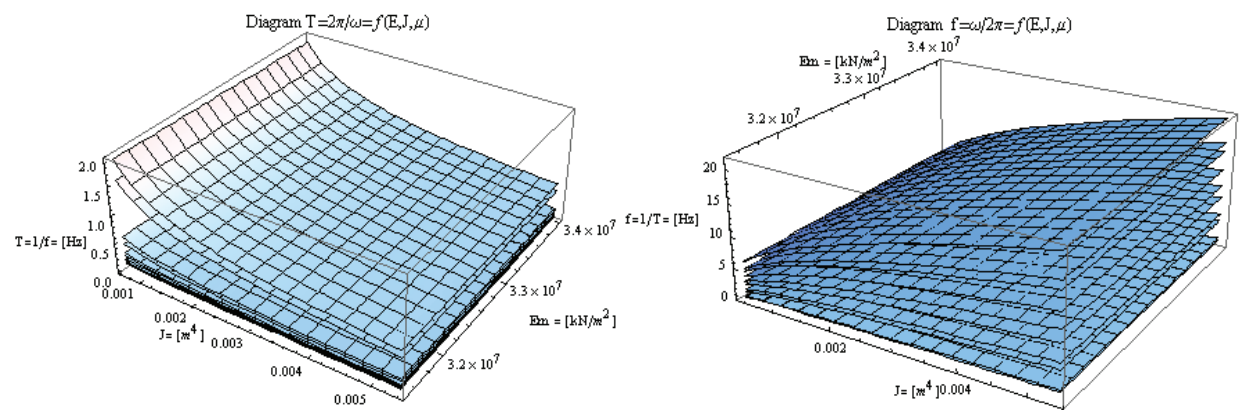

Fig. 3. Diagram of dependence of oscillation periods and eigen frequencies

Em = Interval $\left[\left\{3.15 * 10^{\wedge} 7,3.40 * 10^{\wedge} 7\right\}\right] ; J=$ Interval $\left[\left\{.25 * 0.4 \wedge 3 / 12,0.3 * 0.5^{\wedge} 3 / 12\right\}\right]$; Plot $[\{\operatorname{Max}[(2 \mathrm{Pi}) / \omega[1]], \operatorname{Min}[(2 \mathrm{Pi}) / \omega[1]], \operatorname{Max}[(2 \mathrm{Pi}) / \omega[2]], \operatorname{Min}[(2 \mathrm{Pi}) / \omega[2]], \operatorname{Max}[(2 \mathrm{Pi}) / \omega[3]]$, $\operatorname{Min}[(2 P i) / \omega[3]], \operatorname{Max}[(2 P i) / \omega[4]], \operatorname{Min}[(2 P i) / \omega[4]], \operatorname{Max}[(2 P i) / \omega[5]], \operatorname{Min}[(2 P i) / \omega[5]]\}$, $\{\mu, 0 ., 4\}$, Filling $\rightarrow\{1 \rightarrow\{2\}, 3 \rightarrow\{4\}, 5 \rightarrow\{6\}, 7 \rightarrow\{8\}, 9 \rightarrow\{10\}\}$, AxesLabel $\rightarrow\{" \quad \mu=[t / m] "$, " $\mathrm{T}=2 \pi / \omega=[\mathrm{s}]$ " $\},$ Plothabel $\rightarrow$ "Diagram $\mathrm{T}=2 \pi / \omega=\mathrm{f}(\mathrm{E}, \mathrm{J}, \mu)$ ", PlotRange $\rightarrow\{\{0,, 4\},\{0,1.6\}\}]$ Plot $[\{\operatorname{Max}[\omega[1] / 2 P i], \operatorname{Min}[\omega[1] / 2 P i], \operatorname{Max}[\omega[2] / 2 P i], \operatorname{Min}[\omega[2] / 2 P i], \operatorname{Max}[\omega[3] / 2 P i]$,

$\operatorname{Min}[\omega[3] / 2 \mathrm{Pi}], \operatorname{Max}[\omega[4] / 2 \mathrm{Pi}], \operatorname{Min}[\omega[4] / 2 \mathrm{Pi}], \operatorname{Max}[\omega[5] / 2 \mathrm{Pi}], \operatorname{Min}[\omega[5] / 2 \mathrm{Pi}]\},\{\mu, 0,4\}$, Filling $\rightarrow\{1 \rightarrow\{2\}, 3 \rightarrow\{4\}, 5 \rightarrow\{6\}, 7 \rightarrow\{8\}, 9 \rightarrow\{10\}\}$, AxesLabel $\rightarrow\{" \quad \mu=[\mathrm{t} / \mathrm{m}] ", " \mathrm{f}=1 / \mathrm{T}[\mathrm{Hz}] "\}$, PlotLabel $\rightarrow$ "Diagram $f=f(E, J, \mu) "$, PlotRange $\rightarrow\{\{0,4\},\{0,20\}\}]$ 

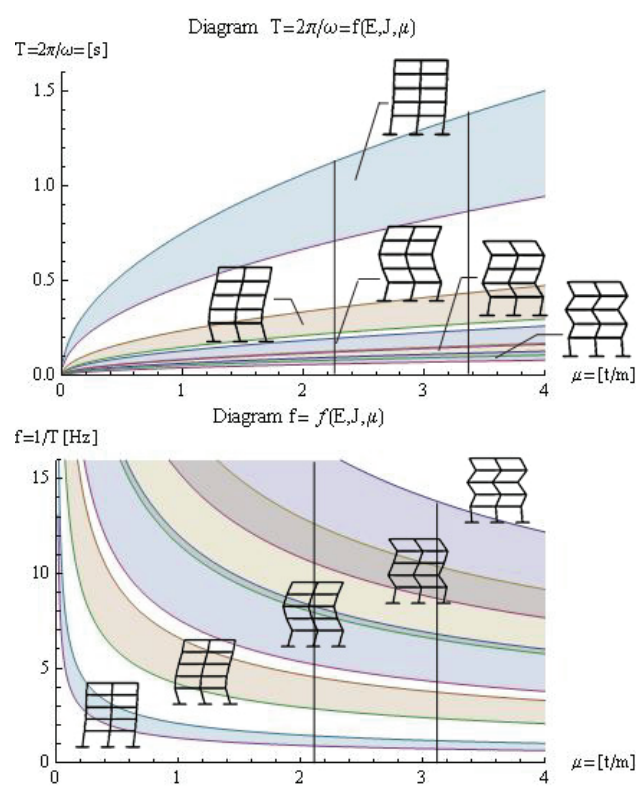

Fig. 4. Diagram of interval of oscillation period and eigen frequencies

The mass concentrated in the nodes, apart from the moment of inertia of the cross section of members, is a dominant factor which affects the variation of periods and frequencies. It is confirmed by a steep change in the graph. The range of dynamic characteristics shows that dispersion is high (interval is wide) and the considerable share in the value of functions of periods and frequencies in real movement range is taken by the magnitude of stiffness of the members and primarily the height of cross section. The intervals of third, fourth and fifth tone are the highest, and they are mutually overlapped. The intervals of higher tones should be taken with reserve, as the procedure of analysis with directly concentrated masses produces considerable error at higher tones.

\section{II-case: Variation of dynamic characteristics of the structure depending on J}
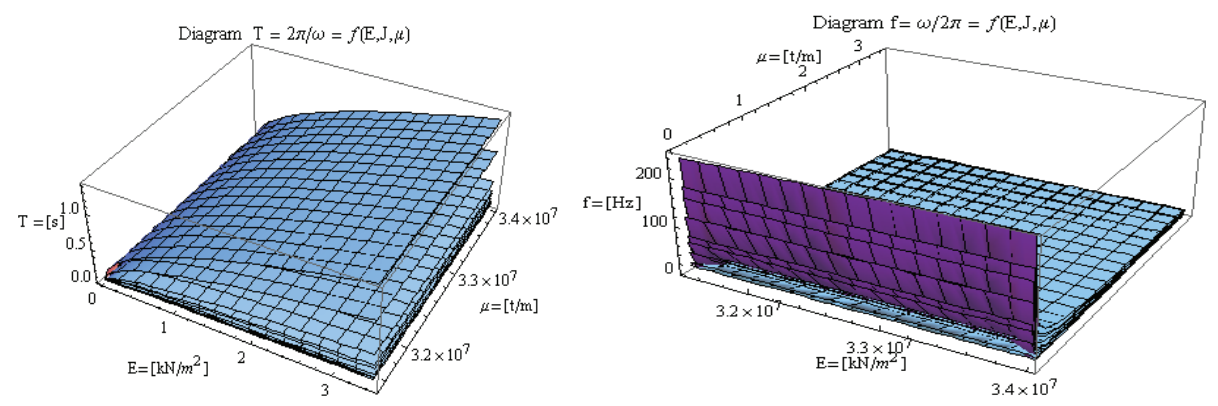

Fig. 5. Diagram of dependence of oscillation periods and eigen frequencies 

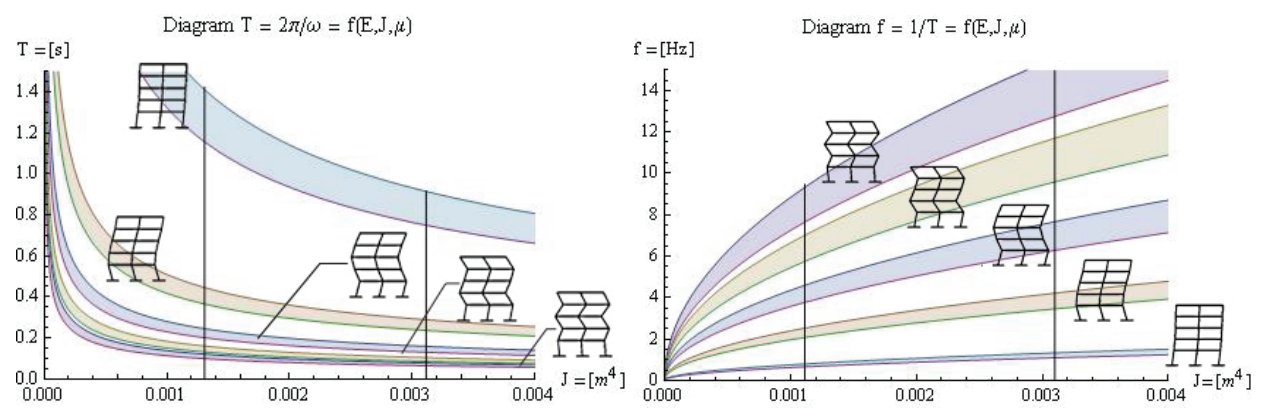

Fig. 6. Diagram of interval of oscillation periods and eigen frequencies in the function of $\mathrm{J}$

The moment of inertia of cross section is a primary factor for its importance, which affects the change of eigen periods and frequencies. The course of change of the graph in terms of real values of the moment of inertia is steep, and the width of the interval is small, which best illustrates the dominance of this factor. The most important property of the graph is that the intervals of tones and periods are more clearly differentiated tan in the first case, which is not the case with variation of the modulus of elasticity which has a marginal effect on dynamical characteristics of linear systems.

\section{III-case: Variation of dynamic characteristics of the structure depending on $\mathbf{E}$}

The influence of the elasticity modulus on the dynamic characteristics is the least. It is such dependency that the change of the concrete class has negligible effects on dynamic characteristics of linear systems. Eigen frequencies and periods of oscillation are in a very large interval. The possibility of change of value of periods of the first tone of oscillation for minimal and maximal values of mass and moment of inertia of the cross section is over $100 \%$. It is lower for the interval of higher tones. From the graphs, it can be concluded that the variation of dynamic characteristics is dominantly affected by the magnitude of masses by the floors and the moment of inertia of cross sections, while the effect of change of the concrete class is negligible.
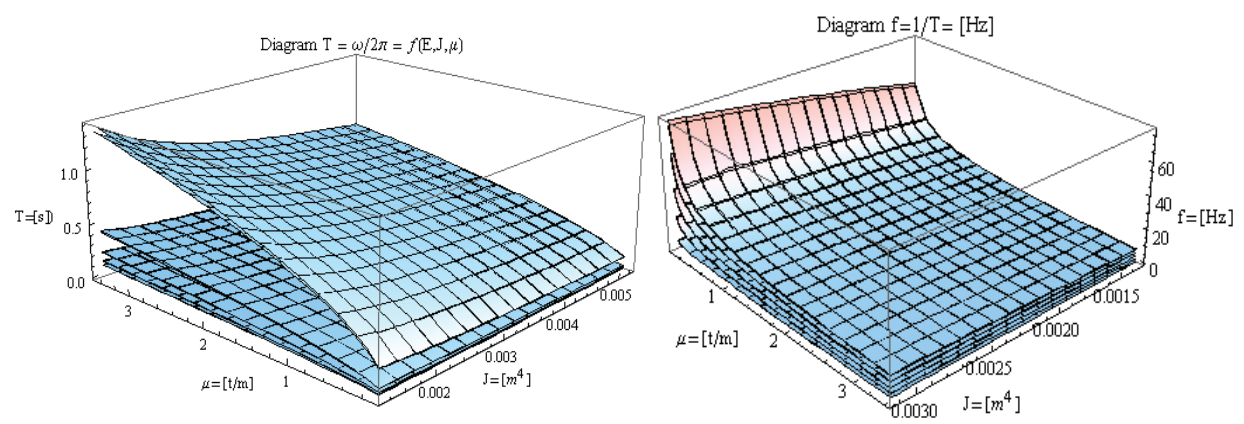

Fig. 7. Diagram of interval of oscillation period and eigen frequencies 

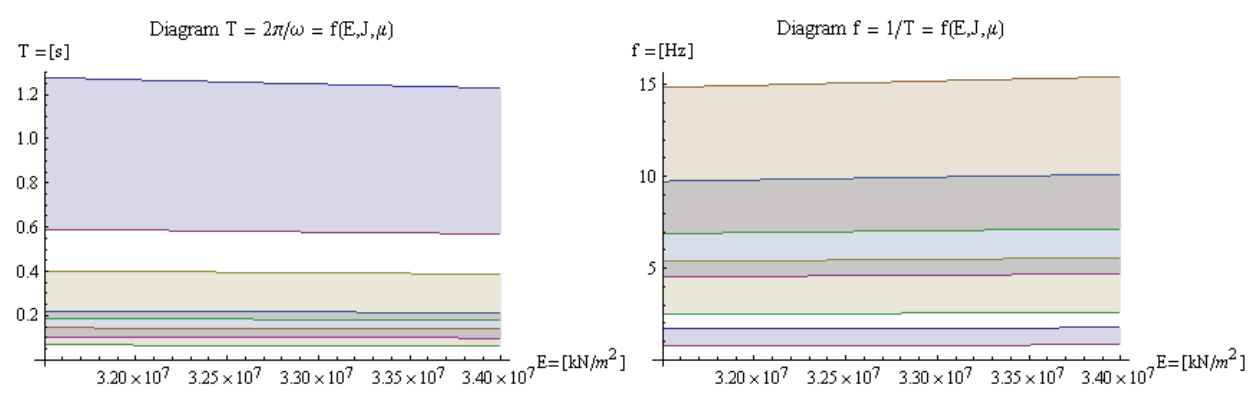

Fig. 8. Diagram of interval of oscillation period and eigen frequencies depending on $\mathrm{E}$

\section{CONCLUSION}

At optimum design of real structure, it is necessary to vary certain parameters in the calculus. Eigen frequencies and forms of oscillations calculated in interval calculus provide a better illustration of dependence on three parameters which were varied. The paper explicitly provides a graphic representation of dynamic characteristics of one real frame system which can be useful in everyday engineering practice. For the finished system stiffness matrix and mass matrix with directly concentrated masses in the nodes, own values and their corresponding vectors were calculated. The following parameters were varied: masses along the length of the members, moment of inertia of cross section and Yung modulus of elasticity. From the given numerical examples, one may observe the dominant influence of the moment of inertia of cross sections, whose variation yields the steepest functions of dynamic characteristics, with the longest intervals. The mass effect is second most important. The diagrams are also extremely steep, and the first three tones are clearly differentiated. Tone coincidence starts from the third tone upwards. The values of frequencies of the tones higher than the first one should be taken with a great reserve, since in the calculus with directly concentrated masses, the dispersion of the results is great. Deviations are several times higher than the accurate values of dynamic characterizes, the obtained dependence tendency is correct. The influence of the modulus of elasticity is the least, and it is reflected in almost horizontal limits of the range being described. The possibility of change of value of periods of the first tone of oscillation for minimal and maximal values of mass and moment of inertia of the cross section is over $100 \%$. Wide intervals at variation of the modulus of elasticity result from the dominance of the moment of inertia of cross section and mass.

On this basis it can be concluded, that for the purpose of as efficient designing, one should adopt stiffness as a main parameter to be varied. In actuality it is done, as it is difficult to affect the floor mass. In the further research, one should separately vary the characteristics of individual members, for instance separately the value of the cross section of columns, and separately the beams and magnitude of mass of corresponding floors. 


\section{REFERENCES}

1. Ćorić B, Ranković S. i Salatić R, Dinamika konstrukcija, Univerzitet u Beogradu, Beograd, 1998., str. 247.

2. Bezuhov, Lužin i Kolkunov, Stabilnost i dinamika konstrukcija u primjerima i zadacima(prevod), Građevinska knjiga, Beograd, 1973., str. 470.

3. Petrović, B., Odabrana poglavlja iz zemljotresnog građevinarstva, Građevinska knjiga, Beograd,1985., str. 180.

4. Clough R.W. and Penzien J., Dynamics of structures, McGRAWHILL BOOK COMPANY, New York, Toronto, p. 634.

5. Maglajlić Z., Simonović G., Hadžović R. i Ademović N., Određivanje osnovne forme i perioda oscilovanja građevina približnim metodama, Materijali i konstrukcije br. 3-4/2006., Beograd, 2006., str. 72-82.

6. Aničić, Fajfar, Petrović, Savits-Nossan, Tomažević, Zemljotresno inženjerstvo visokogradnja, Građevinska knjiga, Beograd, 1990., str. 642.

7. Brice Carnahan, H.A.Luther, James O.Wilkes, Applied Numerical Methods, John Wiley \& sons INC, New York, 1969.

8. Folić R., Neke metode dinamike konstrukcija i njihova primjena u seizmičkoj analizi konstrukcija građevinskih objekata, Građevinski kalendar, Vol. 39, Beograd, prosinac 2006., str. 143-233

9. Wolfram Research, www.wolfram.com.

\section{PRIMENA INTERVALNOG RAČUNA ZA PROCENU DINAMIČKIH KARAKTERISTIKA KONSTRUKCIJA}

\section{Đorđe Đorđević, Predrag Petronijević}

U radu je analizirana primena intervalnog računa u proceni dinamičkih karakteristika linijskih sistema. Na sopstvene periode oscilovanja konstrukcija utiče nekoliko parametara geometrijske karakteristike poprečnog preseka štapova, veličina mase skoncentrisane u etažama i moduo elastičnosti betona. Kao numerički primer je uzeta ramovska armiranobetonska konstrukcija kod koje su navedeni parametri zadani u intervalnom obliku. Rezultat se takođe dobija u intervalnom obliku tako da je moguće pratiti direktan uticaj promenom jednog ili više parametara na vrednost perioda oscilovanja konstrukcija.

Ključne reči: intervalni račun, sopstvene frekfence, matrična formulacija 